\title{
KARAKTERISASI SIFAT FISIS DAN MEKANIS SAMBUNGAN LAS SMAW BAJA A-287 SEBELUM DAN SESUDAH PWHT
}

\author{
Yustiasih Purwaningrum \\ Jurusan Teknik Mesin Fakultas Teknologi Industri \\ Universitas Islam Indonesia Yogyakarta \\ Email : yustiasih2003@yahoo.co.nz
}

\begin{abstract}
The aimed of this research are to compare physical dan mechanical properties between raw materials and Shielded Metal Arc Steel Weld Metals and to find optimum temperature of annealing. A series of Shielded Metal Arc Steel Weld Metals were made on $3 \mathrm{~mm}$ of Thick A 287 carbon steels. The electrode used was E 6013, Ø $3.2 \mathrm{~mm}$. Annealing was performed with three different temperature were $300^{\circ} \mathrm{C}, 600^{\circ} \mathrm{C}$, dan $850^{\circ} \mathrm{C}$. The results show that the tensile strength of raw material had the same value with weld metals and weld metals with annealing $300^{\circ} \mathrm{C}$ and $600^{\circ} \mathrm{C}$, but weld metals with annealing $850^{\circ} \mathrm{C}$ had lower tensile strength. The hardness experiments was used Vickers Micro Hardness. The Hardness number of weld metals was higher than HAZ and raw materials. Weld Metals with annealing $300^{\circ} \mathrm{C}$ had the highest value. The elongation of weld metals and weld metals with annealing $300^{\circ} \mathrm{C}$ and $600^{\circ} \mathrm{C}$ had lower number than raw materials, but weld metals with annealing $850^{\circ} \mathrm{C}$ had almost the same value of elongation with raw materials. The optimum annealing temperature was $850^{\circ} \mathrm{C}$ because weld metals with annealing $850^{\circ} \mathrm{C}$ had high elongation and low tensile strength.

Keywords SMAW, Annealing, Vickers Micro Hardness, Tensile Strength, Elongation.
\end{abstract}

\section{PENDAHULUAN}

Proses pengelasan merupakan proses penyambungan logam yang paling banyak digunakan pada saat ini, karena pengelasan mempunyai banyak keuntungan antara lain : praktis, hasilnya dapat diandalkan, effisien, dan ekonomis. Shielded Metal Arc Welding (SMAW) atau las elektroda terbungkus merupakan proses pengelasan yang paling banyak digunakan.

Hal yang perlu diperhatikan pada hasil pengelasan adalah tegangan sisa, karena pada pengelasan terjadi tegangan thermal karena perbedaan suhu antara logam induk dan daerah las, selain itu tegangan sisa juga terjadi akibat transformasi fasa, karena logam induk yang digunakan adalah baja karbon [1]. Tegangan sisa pada hasil pengelasan disebabkan karena selama siklus thermal las berlangsung, laju pemuaian dan penyusutan di sekitar sambungan las dengan bagian lain yang suhunya relatif lebih dingin tidak sama sehingga menyebabkan perubahan modulus elastisitas E, tegangan luluh, Poisson's ratio [2].

Pembebasan tegangan sisa setelah pengelasan biasanya menggunakan cara annealing. Annealing adalah salah satu jenis PWHT (Post Weld Heat Treatment). Di samping mengurangi tegangan sisa, proses annealing juga dapat memperbaiki 
struktur mikro dan menghindari distorsi dan retak. Proses annealing dilakukan dengan cara memanaskan material pada suhu rekristalisasi, biasanya sekitar 0,5 Tm. Pada baja karbon rendah, suhu rekristalisasi sekitar $450^{\circ} \mathrm{C}<\mathrm{Tc}<700^{\circ} \mathrm{C}$, dan waktu annealing sekitar 1-3 jam.

\section{TUJUAN PENELITIAN}

Tujuan penelitian ini adalah membandingkan sifat fisis dan mekanis antara logam induk dengan hasil las SMAW dan untuk mencari temperatur Annealing paling optimum.

\section{TINJAUAN PUSTAKA}

\subsection{Baja Karbon Rendah}

Logam ferro dapat dikelompokkan menjadi 3 kelompok menurut kadar karbonnya [3] :

- Besi : mempunyai kadar karbon $0-0,008 \%$

- Baja : mempunyai kadar karbon 0,008 - $2 \%$

- Besi cor : mempunyai kadar karbon 2 - 4,5\%

\subsection{Shielded Metal Arc Welding (SMAW)}

Las Busur Rendam (SMAW) adalah proses pengelasan dimana panas dihasilkan dari busur listrik antara ujung elektroda dengan logam yang dilas.

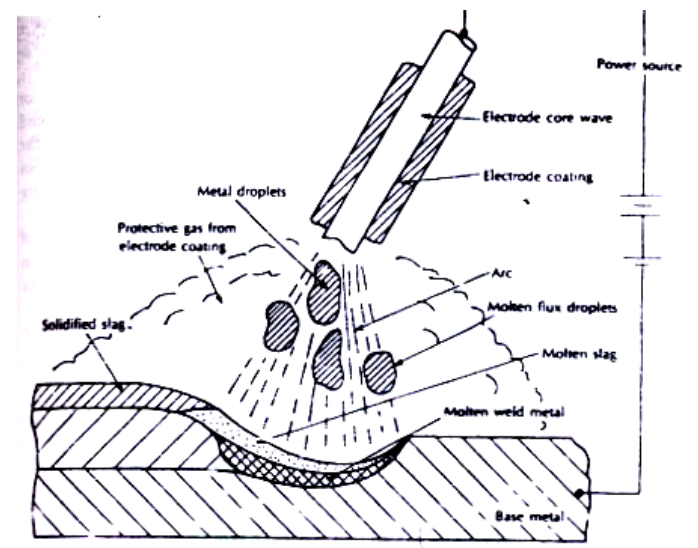

Gambar 1 : Prinsip dasar pengelasan SMAW [1]

Elektroda SMAW terdiri dari 2 bagian yaitu bagian inti yang terbuat dari baja yang berfungsi sebagai bahan pengisi (filler) dan bahan pembungkus yang disebut fluks. Fungsi dari fluks adalah : sebagai sumber terak untuk melindungi logam cair dari udara sekitarnya, menjaga busur listrik agar tetap stabil, sebagai deoksidator, menghasilkan gas pelindung, mengurangi percikan api dan uap pada pengelasan, dan sebagai sumber dari unsur paduan. 


\subsection{Post Weld Heat Treatment (PWHT)}

Post Weld Heat Treatment adalah proses pemanasan dan pendinginan pada logam untuk mendapatkan sifat-sifat tertentu yang diperlukan untuk suatu konstruksi, misalnya kekuatan (strength), kelunakkan (softness), memperhalus ukuran butir.

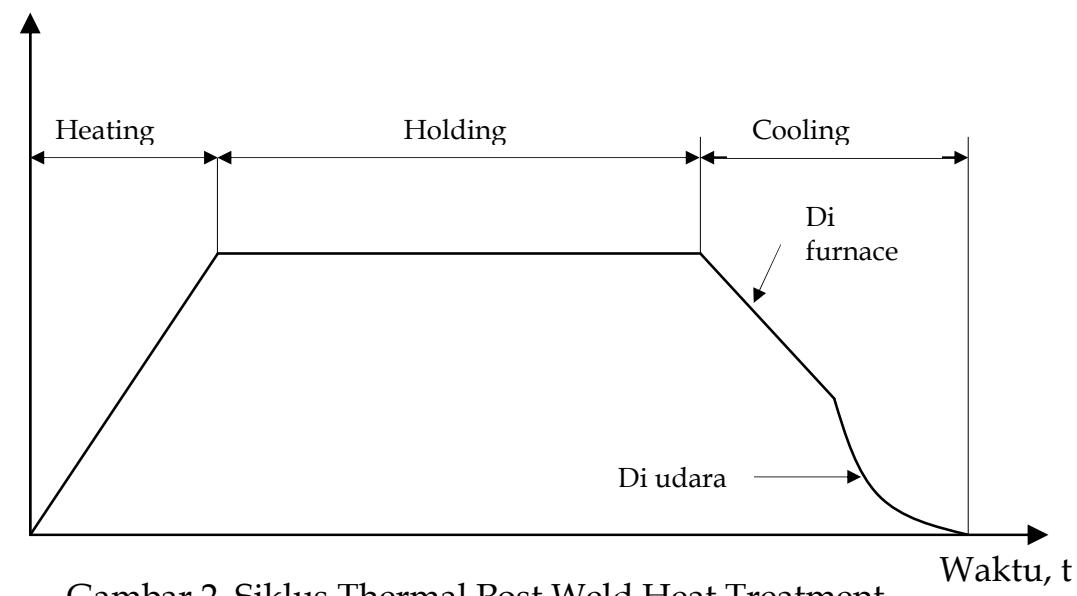

Gambar 2. Siklus Thermal Post Weld Heat Treatment

Prinsip dasar proses PWHT [4]adalah :

- Heating merupakan proses pemanasan sampai temperatur diatas atau dibawah temperatur kritis suatu material

- Holding adalah menahan material pada temperatur pemanasan untuk memberikan kesempatan adanya perubahan struktur mikro.

- Cooling adalah mendinginkan dengan kecepatan tertentu tergantung pada sifat akhir material yang diinginkan.

Annealing (anil) adalah proses PWHT yang mempunyai tujuan untuk memperbaiki keuletan dan menurunkan tegangan tarik [4]. Annealing dilakukan dengan cara memanaskan material didalam furnace sampai suhu tertentu kemudian ditahan pada suhu tersebut, dan pendinginan dilakukan didalam furnace.

\subsection{Pengujian Tarik}

Dari pengujian tarik dapat diperoleh grafik tegangan-regangan, yang dapat digunakan untuk memperoleh data kekuatan tarik, regangan, daerah elastis, daerah plastis, tegangan luluh, tegangan maksimum, dan tegangan patah. 


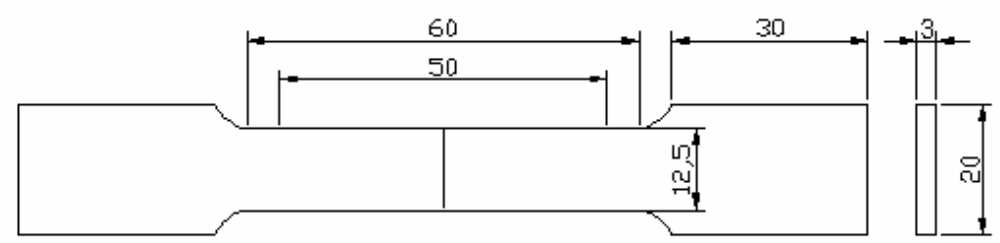

Gambar 3. Spesimen Uji Tarik [5]

\subsection{Pengujian Kekerasan}

Pengujian kekerasan dilakukan dengan menggunkan metode Vickers Micro Hardness. Keuntungan pengujian kekerasan dengan metode Vickers adalah : bekas penekanannya kecil, pengukurannnya teliti, dan range ukurnya besar. Pengujian dilakukan untuk membandingkan nilai kekerasan pada raw material, spesimen las, spesimen yang dilas dengan temperatur anil $300^{\circ} \mathrm{C}, 600^{\circ} \mathrm{C}$, dan $850^{\circ} \mathrm{C}$ pada daerah las, HAZ, dan logam induk. Angka kekerasan Vickers dapat ditentukan dengan persamaan berikut :

$$
\mathrm{VHN}=\frac{2 F \sin \frac{\theta}{2}}{d^{2}}=1,8544 \frac{F}{d^{2}}
$$

Dimana: $\quad F$ : beban yang dipergunakan (kgf)

$\mathrm{d}$ : panjang diagonal rata-rata $(\mu \mathrm{m})$

$\theta$ : sudut antara permukaan intan yang berlawanan $=136^{\circ}$

Prinsip dasar pengujian kekerasan dengan vickers micro hardness, dari hasil penumbukan akan diperoleh satu bekas injakan penumbuk pada benda uji. Bekas injakan ini kemudian diukur panjang diagonal (d). Besar diagonal rata-rata dimasukkan ke persamaan 2, dan hasilnya akan diperoleh angka kekerasan Vickers.

\subsection{Pengamatan Struktur Mikro}

Pengamatan struktur mikro adalah salah satu sifat fisis yang diamati dalam penelitian ini. Tujuan dari pengamatan struktur mikro adalah untuk mengetahui struktur mikro raw material, hasil pengelasan tanpa anil, dan hasil pengelasan dengan variasi temperatur anneling yaitu $300^{\circ} \mathrm{C}, 600^{\circ} \mathrm{C}$, dan $850^{\circ} \mathrm{C}$. Pengamatan struktur mikro dilakukan dengan menggunakan mikrosokop optik.

Langkah-langkah persiapan benda uji sesuai dengan prosedur standar yang meliputi penggerindaan, pengamplasan, pemolesan, dan pengetsaan dengan menggunakan $\mathrm{HNO}_{3}(2,5 \%)$. 


\section{METODE PENELITIAN}

\subsection{Bahan dan Alat}

Material yang dipakai adalah pelat baja A-287 dengan tebal $3 \mathrm{~mm}$. Elektroda yang digunakan adalah E 6013 diameter 3,2 mm. Alat yang dipakai : Mesin Las listrik DC, Mikroskop Optik, Vickers Micro Hardness, Alat Uji Tarik, Alat Ukur, Furnace.

\subsection{Diagram Alir Penelitian}

Berikut ini adalah diagram alir penelitian :

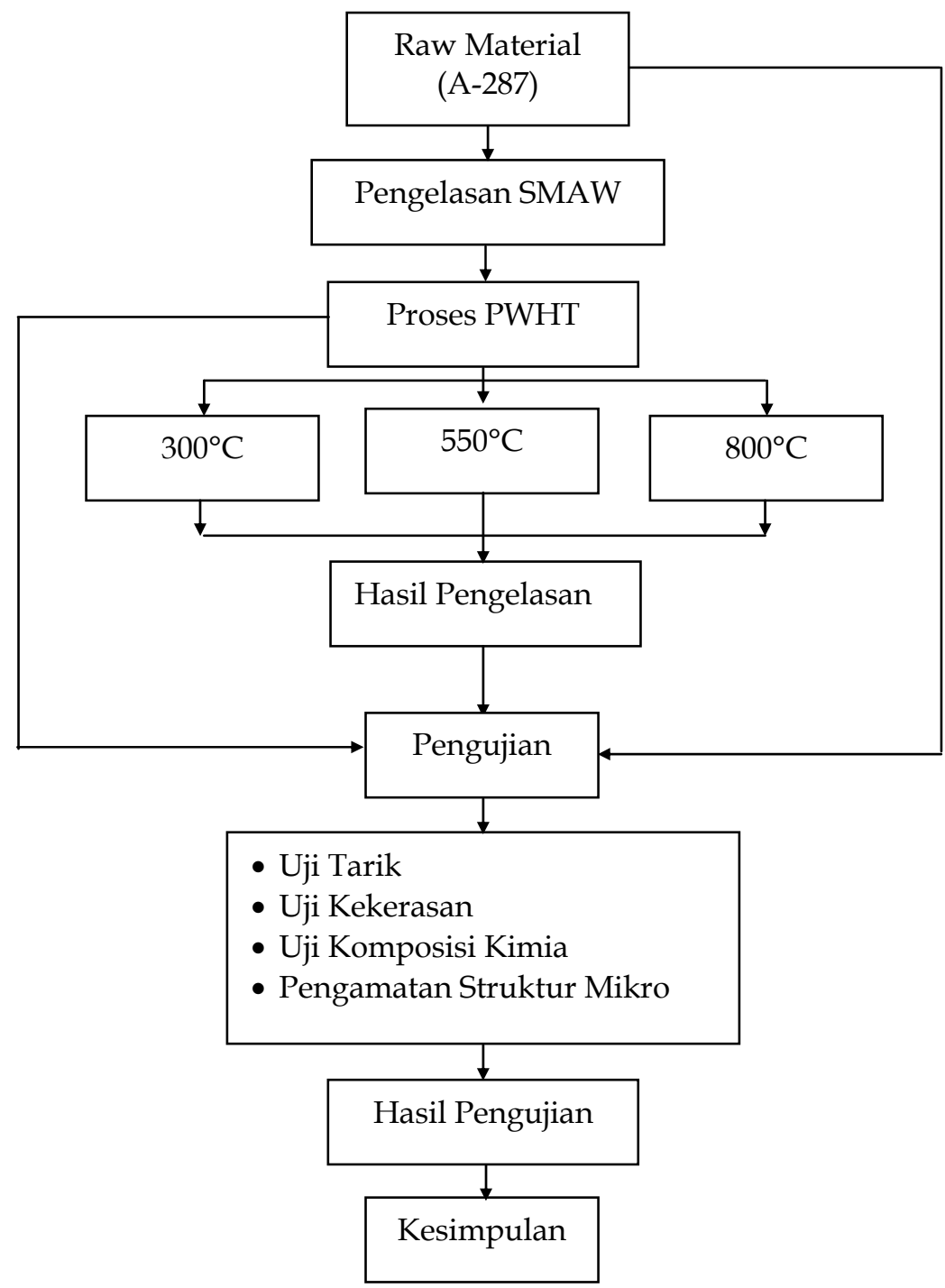

Gambar 4. Diagram alir penelitian 


\section{HASIL DAN PEMBAHASAN}

\subsection{Pengujian Komposisi Kimia}

Pengujian komposisi kimia dilakukan pada raw material dan hasil las tanpa perlakuan panas. Untuk setiap spesimen dilakukan 3 kali pengujian. Berikut ini adalah hasil pengujian komposisi kimia :

Tabel 1. Hasil pengujian komposisi kimia

\begin{tabular}{|c|c|c|c|c|c|c|c|}
\hline \multicolumn{4}{|c|}{ Raw Material } & \multicolumn{4}{c|}{ Hasil Las } \\
\hline $\mathrm{C}$ & 0,093 & $\mathrm{Mo}$ & 0,004 & $\mathrm{C}$ & 0,089 & $\mathrm{Mo}$ & $<0,004$ \\
\hline $\mathrm{Si}$ & 0,192 & $\mathrm{Cu}$ & $<0,004$ & $\mathrm{Si}$ & 0,013 & $\mathrm{Cu}$ & $<0,004$ \\
\hline $\mathrm{Mn}$ & 0,453 & $\mathrm{Al}$ & 0,001 & $\mathrm{Mn}$ & 0,276 & $\mathrm{Al}$ & 0,010 \\
\hline $\mathrm{P}$ & 0,015 & $\mathrm{Nb}$ & 0,009 & $\mathrm{P}$ & 0,013 & $\mathrm{Nb}$ & 0,008 \\
\hline $\mathrm{S}$ & 0,015 & $\mathrm{~W}$ & 0,041 & $\mathrm{~S}$ & 0,017 & $\mathrm{~W}$ & 0,043 \\
\hline $\mathrm{Ni}$ & 0,031 & $\mathrm{Ti}$ & 0,013 & $\mathrm{Ni}$ & 0,040 & $\mathrm{Ti}$ & 0 \\
\hline $\mathrm{Cr}$ & 0,023 & $\mathrm{Co}$ & 0,011 & $\mathrm{Cr}$ & 0,019 & $\mathrm{Co}$ & 0,015 \\
\hline
\end{tabular}

Semua dalam \% berat

Dari hasil pengujian komposisi kimia dapat dihitung harga CE (Carbon Equivalent) [3]

$$
\begin{aligned}
C E & =\% C+\frac{(\% M n+\% S i)}{6}+\frac{(\% C r+\% M o)}{5}+\frac{(\% N i+\% C u)}{15} \ldots \ldots . . . \\
& =0,093+\frac{(0,453+0,192)}{6}+\frac{(0,023+0,004)}{5}+\frac{(0,031+0,004)}{15} \\
& =0,208
\end{aligned}
$$

Dari hasil perhitungan dapat dilihat bahwa baja tersebut mempunyai sifat mampu las yang baik karena mempunyai nilai $\mathrm{CE}<0,4$. Baja karbon dengan harga $\mathrm{CE}$ rendah mempunyai mampu las yang tinggi. Semakin rendah harga $\mathrm{CE}$ semakin rendah pula kepekaan terhadap retak dingin pada sambungan las dan HAZ.

Dari hasil pengujian komposisi kimia terlihat bahwa hampir semua unsur untuk raw material dan hasil las tanpa annealing mempunyai nilai hampir sama, kecuali unsur Si dan Mn. Perbedaan tersebut disebabkan karena pada hasil las komposisi kimianya tercampur dengan inti elektroda (filler) yang mencair.

\subsection{Pengujian Tarik}

Pengujian Tarik dilakukan sebanyak 7 spesimen tiap satu perlakuan. Berikut ini adalah grafik nilai rata-rata hasil pengujian tarik : 


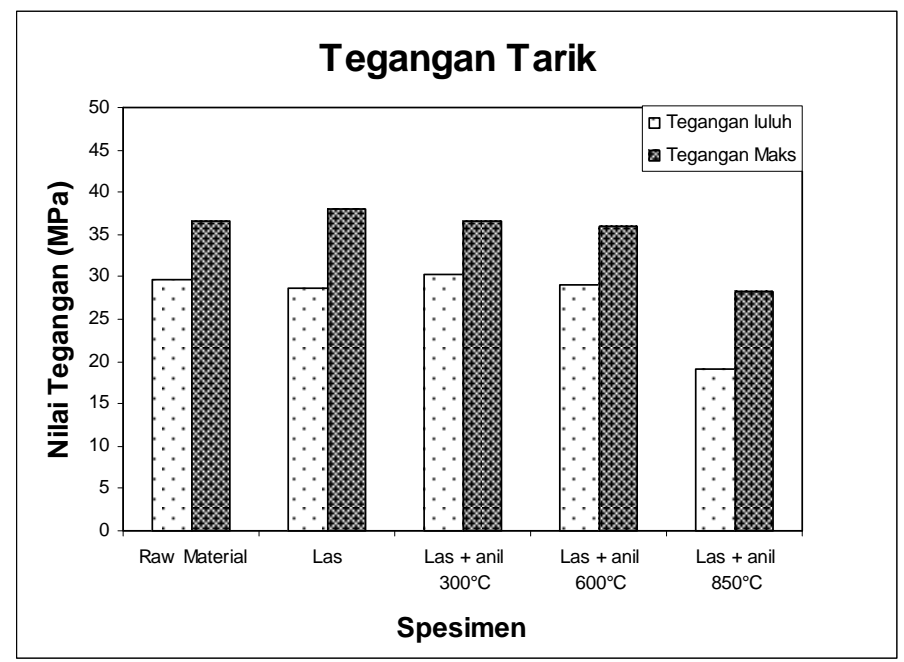

Gambar 5. Grafik Tegangan Tarik

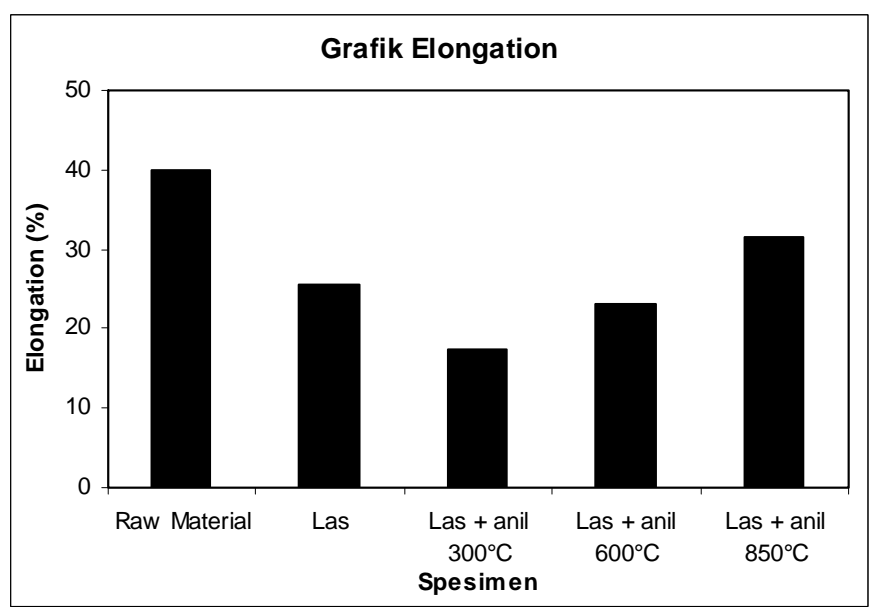

Gambar 6. Grafik Elongation (Perpanjangan)

Dari hasil pengujian tarik dapat terlihat bahwa kekuatan tarik raw material, hasil las, hasil las dengan anil $300^{\circ} \mathrm{C}$, dan hasil las dengan anil $600^{\circ} \mathrm{C}$ hampir sama nilainya, karena proses heating pada anil $300^{\circ} \mathrm{C}$ dan anil $600^{\circ} \mathrm{C}$ belum mencapai titik kritisnya sehingga belum terjadi perubahan struktur mikro. Sedangkan pada hasil las dengan anil $850^{\circ} \mathrm{C}$, nilai kekuatan tariknya lebih rendah dibandingkan dengan yang lain.

Dari Gambar 6. terlihat bahwa hasil pengelasan mempunyai nilai perpanjangan lebih rendah jika dibandingkan dengan raw materialnya. Sedangkan setelah dilakukan proses anil, hasil las dengan anil $850^{\circ} \mathrm{C}$ mempunyai nilai perpanjangan paling tinggi jika dibandingkan dengan anil pada suhu yang lain.

Pada pengujian tarik, semua spesimen patah pada logam induk, hal tersebut menunjukkan bahwa proses pengelasan berjalan dengan baik. 


\subsection{Pengujian Kekerasan}

Pengujian kekerasan dilakukan secara acak dengan menggunakan Vickers Micro Hardness, untuk setiap daerah pengelasan dilakukan 7 kali pengujian setiap spesimen. Jumlah spesimen 2 buah. Berikut ini adalah grafik hasil pengujian kekerasan :

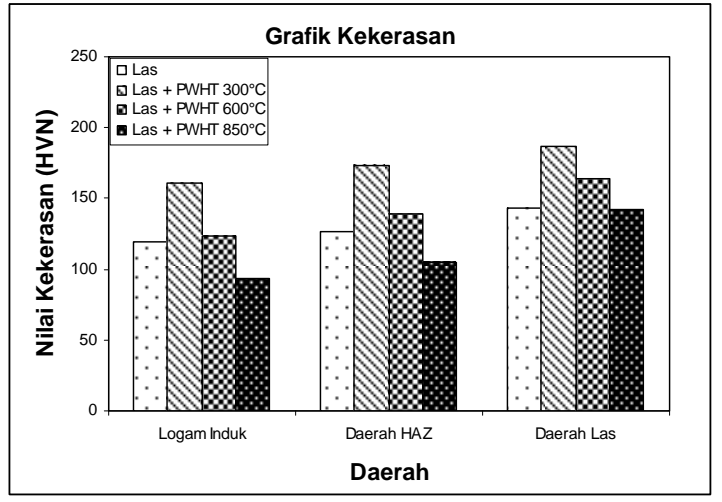

Gambar 7. Grafik Nilai Kekerasan

Dari hasil pengujian kekerasan terlihat bahwa spesimen dengan las dengan anil $300^{\circ} \mathrm{C}$ mempunyai nilai kekerasan paling tinggi dibandingkan dengan spesimen yang lain. Hal tersebut sesuai dengan hasil pengujian tarik yang dilakukan, yaitu mempunyai nilai perpanjangan yang paling rendah. Karena semakin tinggi nilai kekerasan suatu material maka semakin rendah nilai perpanjangannya.

Pada semua spesimen nilai kekerasan pada daerah las lebih tinggi dibandingkan dengan daerah HAZ dan daerah logam induk.

\subsection{Pengamatan Struktur Mikro}

Berikut ini adalah gambar hasil pengamatan struktur mikro :

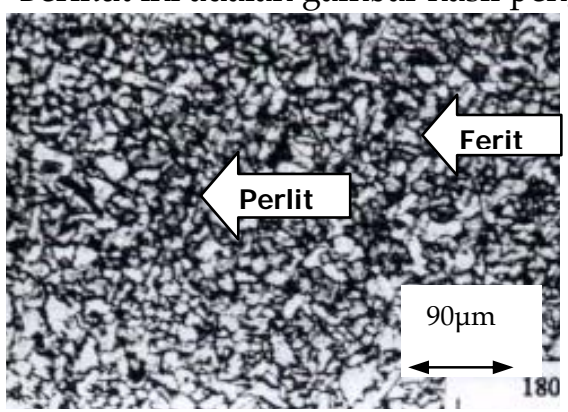

(a)

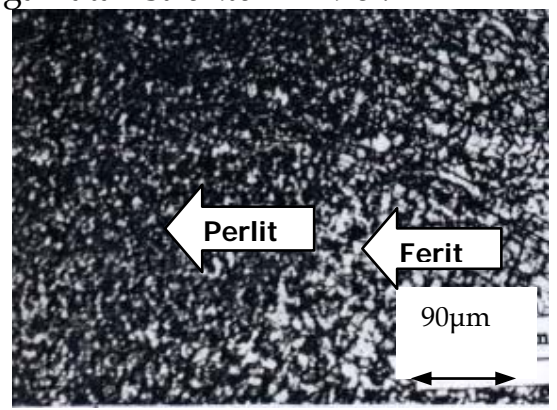

(b) 


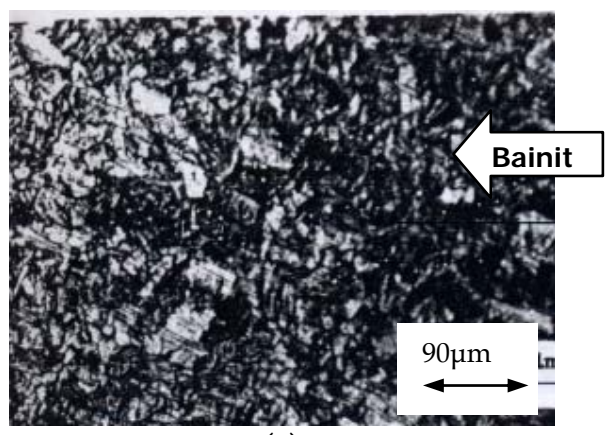

(c)

Gambar 8. Hasil pengujian struktur mikro hasil las dengan anil $300^{\circ} \mathrm{C}$
(a) Logam induk
(b) Daerah HAZ
(c) Daerah Las

Dari gambar 8 terlihat bahwa struktur mikro pada logam induk dan daerah HAZ adalah sama yaitu berupa ferit yang berwarna putih dan perlit yang berwarna hitam, tetapi ukuran butir ferit dan perlit pada daerah HAZ lebih kecil. Daerah HAZ (Heat Affected Zone) adalah logam induk yang terkena panas pengelasan. Panas pengelasan menyebabkan proses rekristalisasi pada daerah HAZ.

Sedangkan pada daerah las struktur mikro yang terbentuk adalah bainit. Bainit mempunyai kekerasan lebih tinggi dibandingkan dengan ferit dan perlit [6].

\section{SIMPULAN}

Dari pengujian diatas dapat diambil kesimpulan sebagai berikut :

- Nilai kekuatan tarik logam induk, hasil pengelasan, dan hasil pengelasan dengan anil $300^{\circ} \mathrm{C}$ dan anil $600^{\circ} \mathrm{C}$ mempunyai nilai hampir sama.

- Temperatur anil yang paling optimum adalah $850^{\circ} \mathrm{C}$, karena hasil pengujian dengan anil suhu $850^{\circ} \mathrm{C}$ mempunyai nilai perpanjangan paling tinggi dan kekuatan tarik paling rendah, hal tersebut sesuai dengan tujuan utama anil yaitu memperbaiki keuletan dan menurunkan tegangan tarik.

- Kekerasan daerah las mempunyai nilai lebih tinggi dibandingkan dengan daerah HAZ dan daerah logam induk.

- Nilai kekerasan paling tinggi terdapat pada hasil las dengan anil $300^{\circ} \mathrm{C}$.

- Struktur mikro pada logam induk dan daerah HAZ berupa ferit dan perlit, sedangkan pada daerah HAZ berupa bainit.

\section{UCAPAN TERIMA KASIH}

Ucapan terima kasih penulis ucapkan kepada seluruh staf Pertamina UP IV Cilacap.

\section{PUSTAKA}

[1] Messler, R.W., (1999) Principles of Welding (Processes, Physics, Chemistry, and Metallurgy), John Wiley and Sons, United States 
[2] Easterling,K.E., (1992) Introduction to the Physical Metallurgy of Welding, Butterworth-Heinemann, London, UK

[3] Wiryosumarto H., dan Okumura, T., (2000) Teknologi Pengelasan Logam, PT.Pradnya Paramita, Jakarta

[4] Sadminto, (1999) Teknologi dan Inspeksi Las, Dinas Jasa Teknik Direktorat Pengolahan Pertamina Pusat, Jakarta

[5] Anonim, (1981) JIS Handbook, Japan Standards Asociation, Japan

[6] Abson, D.J., dan Pargeter, R.J., (1986) Factors Influencing As-deposited Strength, Microstructure, and Toughness of Manual Metal Arc Welds Suitable for C-Mn Steel Fabrications, International Metals Reviews, Volume 31, pp 141-189 